\title{
Spatial Variability and Periodicity of Precipitation in the Middle Reaches of the Yellow River, China
}

\author{
Yi He, ${ }^{1}$ Xingmin Mu, ${ }^{1,2,3}$ Peng Gao, ${ }^{2,3}$ Guangju Zhao, ${ }^{2,3}$ Fei Wang, \\ Wenyi Sun, ${ }^{2,3}$ and Yuqing Zhang ${ }^{4}$ \\ ${ }^{1}$ College of Water Resources and Architectural Engineering, Northwest A\&F University, Yangling, Shaanxi 712100, China \\ ${ }^{2}$ Institute of Soil and Water Conservation, Northwest A\&F University, Yangling, Shaanxi 712100, China \\ ${ }^{3}$ Institute of Soil and Water Conservation, Chinese Academy of Sciences and Ministry of Water Resources, Yangling, \\ Shaanxi 712100, China \\ ${ }^{4}$ School of Atmospheric Science, Nanjing University of Information Science \& Technology, Nanjing 210044, China
}

Correspondence should be addressed to Xingmin Mu; xmmu@ms.iswc.ac.cn and Wenyi Sun; sunwy@ms.iswc.ac.cn

Received 30 April 2015; Revised 3 June 2015; Accepted 10 June 2015

Academic Editor: Steffen Mischke

Copyright (c) 2016 Yi He et al. This is an open access article distributed under the Creative Commons Attribution License, which permits unrestricted use, distribution, and reproduction in any medium, provided the original work is properly cited.

Rainfall is one of the most important reasons causing the soil erosion in the Loess Plateau. The precipitation across the most severely eroded areas in middle reaches of the Yellow River (MRYR), China, was investigated by analyzing the precipitation of flood season $\left(P_{f}\right)$ and precipitation of main flood season $\left(P_{\mathrm{mf}}\right)$ from 26 meteorological stations during the period from 1958 to 2013 . The empirical orthogonal function (EOF), ensemble empirical mode decomposition, and Hurst exponent are used to detect spatial, multiscale characteristics of periodicity and trend for precipitation. The results show that there exist quasi-3- and quasi-6-year interannual periods and quasi-11- and quasi-28-year interdecadal scale periods for $P_{f}$ and $P_{\mathrm{mf}}$. However, periodical features in most of the study area are not statistically noticeable. Moreover, first EOFs indicated precipitation was affected by the large-scale circulation patterns, and the spatial patterns of the second EOFs indicated an obviously north-south gradient in the MRYR, whereas the third EOFs displayed east-west patterns. Hurst exponent analysis indicates that precipitation in $P_{f}$ and $P_{\mathrm{mf}}$ will continue the current trends in the future. These findings can provide important implications for ecological restoration and farming operations across the study region.

\section{Introduction}

Time series analysis of hydroclimatic observations provides direct information about hydrological changes and, therefore, plays a key role in understanding and managing water resources. Increasing knowledge is needed on large-scale variations of hydrological variables and water cycle parameters in order to assess their potential impact on water resources availability and hydrologic hazards. Precipitation is a major factor in agriculture and in recent years interest has increased in learning about precipitation variability for periods of months to years. Therefore, the spatial and temporal variability of the precipitation time series is important from both the scientific and practical point of view $[1,2]$.

For the last several years, a number of researches have been used to measure rainfall variability with various approaches in many different regions in the world; for example, Barros et al. [3] showed that most of the annual precipitation trends since 1960 in the Southern South America to the east of the Andes region could be described by the first two rainfall eigenvectors of the principal component analysis (PCA). Coulibaly [4] used the wavelet and cross-wavelet to identify and describe spatial and temporal variability in Canadian seasonal precipitation and gained further insights into the dynamical relationship between the seasonal precipitation and the dominant modes of climate variability in the northern hemisphere. Feidas et al. [5] analyzed the precipitation in Greece and found that there was a link between precipitation variability in Greece and the Mediterranean pressure oscillation. Modarres and da Silva [6] analyzed the time series of annual rainfalls, number of rainy-days per year, and monthly rainfall of 20 stations by 
the Mann-Kendall test to assess climate variability in the arid and semiarid regions of Iran. Liu et al. [7] investigated the spatial and temporal patterns of the precipitation trends in the Yellow River Basin, China, and showed a decreasing trend in most of stations. Li et al. [8] evaluated the variation of annual and seasonal precipitation by using the Mann-Kendall test and Hurst exponent methods in Xinjiang, China. Xue et al. [9] decomposed the autumn precipitation series by using ensemble empirical mode decomposition (EEMD) method in the Weihe River Basin and got the period characteristics of multiscales in precipitation. Yu et al. [10] investigated precipitation signals and its impact assessment on soil hydrological process by using Hilbert-Huang transform and continuous wavelet transform approaches.

The Yellow River is noted for its small water and huge sediment discharge in the world. The middle reaches of the Yellow River flow through the Loess Plateau, rainfall is one of the most important reasons causing the soil erosion in this region. The water from the middle reaches accounted for $44.3 \%$ of the Yellow River streamflow, but the sediment has accounted for $88.2 \%$ of the Yellow River sediment [11]. The annual average sediment discharge of the Yellow River was $16 \times 10^{8} \mathrm{t}$ (according to the observed data from Shan County hydrological station during 1919-1960). In recent years, many studies have reported significant decrease beyond expectations in streamflow and sediment discharge in the Middle Yellow River [11-17]. The observed average annual streamflow form Toudaoguai station to Tongguan station (located in the Middle Yellow River) was $124.9 \times 10^{8} \mathrm{~m}^{3}$ during 19522013, while it was $68.9 \times 10^{8} \mathrm{~m}^{3}$ during 2000-2013. The 56.0 $\times 10^{8} \mathrm{~m}^{3}$ decrease in streamflow accounted for $44.8 \%$ of the average annual streamflow (1952-2013) (the Ministry of Water Resources of China, 2014).

So far, most of the studies for precipitation variation were focused on analysis in yearly, while fewer studies were conducted on the periodicity of precipitation time series for identifying climate change signals in the middle reaches of the Yellow River. The periodicity of precipitation is a key factor for soil erosion, especially in the Loess Plateau. Therefore, the objectives of this study were to investigate temporal and spatial variation characteristics of precipitation of flood season precipitation $\left(P_{f}\right)$ and precipitation of main flood season $\left(P_{\mathrm{mf}}\right)$ using monthly precipitation datasets from 1958 to 2013 and to explore the trends of $P_{f}$ and $P_{\mathrm{mf}}$ in the future by Hurst exponent. The results may have important implications on water management and environmental phenomena, such as soil instability, erosion, and desertification.

\section{Study Area and Data}

2.1. Study Region. The study area is situated in the arid and subhumid Loess Plateau region in the middle reaches of the Yellow River (MRYR), between Hekouzhen (Toudaoguai) and Tongguan section, with an area of $290000 \mathrm{~km}^{2}$ between $104^{\circ}-113^{\circ} \mathrm{E}$ and $32^{\circ}-40^{\circ} \mathrm{N}$, accounting for $38 \%$ of Yellow River Basin area. It encompasses parts of 159 counties, across the Ningxia Hui Autonomous Region (Ningxia), Shanxi, Inner Mongolia Autonomous Region (Inner Mongolia), and the
TABLE 1: Geographical coordinates, annual mean precipitation $\left(P_{y}\right)$ for 26 meteorological stations across the middle reaches of the Yellow River.

\begin{tabular}{|c|c|c|c|c|}
\hline Station (abbreviation) & $\begin{array}{l}\text { Latitude } \\
\left({ }^{\circ} \mathrm{N}\right)\end{array}$ & $\begin{array}{c}\text { Longitude } \\
\left({ }^{\circ} \mathrm{E}\right)\end{array}$ & $\begin{array}{c}\text { Elevation } \\
(\mathrm{m})\end{array}$ & $P_{y}(\mathrm{~mm})$ \\
\hline Youyu (YY) & 40.00 & 112.45 & 1345.8 & 421.6 \\
\hline Hequ (HQ) & 39.38 & 111.15 & 861.5 & 410.4 \\
\hline Wuzhai (WZ) & 38.92 & 111.82 & 1401.0 & 472.5 \\
\hline Xingxian (XX) & 38.47 & 111.13 & 1012.6 & 492.9 \\
\hline Yulin (YL) & 38.27 & 109.78 & 1157.0 & 406.9 \\
\hline Taiyuan (TY) & 37.78 & 112.55 & 778.3 & 443.7 \\
\hline Hengshan (HS) & 37.93 & 109.23 & 1111.0 & 377.6 \\
\hline Suide (SD) & 37.50 & 110.22 & 929.7 & 452.7 \\
\hline Lishi (LS) & 37.50 & 111.10 & 950.8 & 491.1 \\
\hline Jiexiu (JX) & 37.03 & 111.92 & 743.9 & 465.5 \\
\hline Wuqi (WQ) & 36.92 & 108.17 & 1331.4 & 469.0 \\
\hline Yan'an (YA) & 36.60 & 109.50 & 958.5 & 542.7 \\
\hline Xixian (XX) & 36.70 & 110.95 & 1052.7 & 524.5 \\
\hline Linfen (LF) & 36.07 & 111.50 & 449.5 & 484.7 \\
\hline Huanxian (HX) & 36.58 & 107.30 & 1255.6 & 434.2 \\
\hline Luochuan (LC) & 35.82 & 109.50 & 1159.8 & 612.3 \\
\hline Yuncheng (YC) & 35.05 & 111.05 & 365.0 & 528.6 \\
\hline Xiji (XJ) & 35.97 & 105.72 & 1916.5 & 410.3 \\
\hline Pingliang (PL) & 35.55 & 106.67 & 1346.6 & 501.3 \\
\hline Xifeng $(\mathrm{XF})$ & 35.73 & 107.63 & 1421.0 & 550.3 \\
\hline Changwu (CW) & 35.20 & 107.80 & 1206.5 & 581.3 \\
\hline Tongchuan (TC) & 35.08 & 109.07 & 978.9 & 581.6 \\
\hline Tianshui (TS) & 34.58 & 105.75 & 1141.7 & 522.4 \\
\hline Baoji (BJ) & 34.35 & 107.13 & 612.4 & 655.7 \\
\hline Wugong (WG) & 34.25 & 108.22 & 447.8 & 602.7 \\
\hline Xian (XA) & 34.30 & 108.93 & 397.5 & 556.7 \\
\hline
\end{tabular}

Gansu and Shaanxi provinces. The natural environment is featured by a gradual increase in precipitation from northwest to southeast, concentrated mainly in summer, and dominated usually in the form of rainstorms. A digital elevation model (DEM) of the region is shown in Figure 1. The annual sediment transportation into the Yellow River accounts for $90 \%$ of the total sediment discharge, making the MRYR one of the most soil-eroded areas of the Loess Plateau. The area has thick $(50-80 \mathrm{~m})$ loess layers. The particle composition is mainly fine sand, silt (up to $50 \%$ of the total), and clay. The loess has high porosity and is prone to landslides. The soil is typical black loam soil with a loose structure that is readily degraded [18].

2.2. Data. The daily and monthly rainfall data of 26 national meteorological stations (apart from the mountain station) used in this work were extracted from the National Meteorological Information Centre (NMIC) (Table 1 and Figure 1), including daily precipitation $\left(P_{d}, \mathrm{~mm}\right)$, monthly precipitation $\left(P_{m}, \mathrm{~mm}\right)$, and yearly precipitation $\left(P_{y}, \mathrm{~mm}\right)$ from 1958 to 2013. The dataset has been quality ensured by NMIC. We 


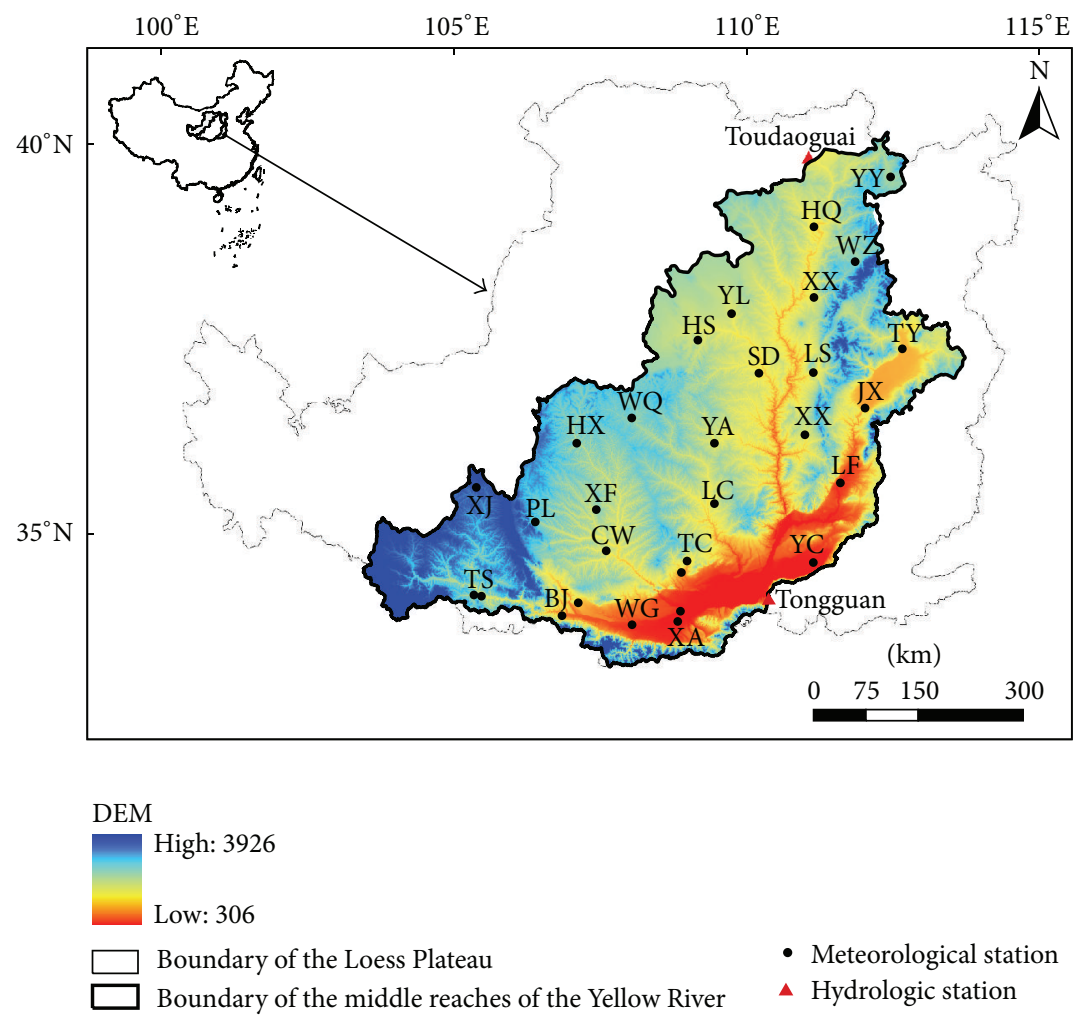

FIGURE 1: Location of the selected 26 meteorological stations on a DEM of middle reaches of the Yellow River, China.

performed further routine quality assessment and error correction procedures on the data following methods described by Peterson et al. [19]. Missing values are infrequent (during certain months in 1968 precipitation data was missing from Wuqi station, during certain months in 1969 precipitation data was missing from Lishi station, and during one month in 2013 precipitation data was missing from Baoji station). The missing data in these three stations were processed in the following ways: (1) if data were missing only for 1 day, the missing data were replaced by the average value of its neighboring days and (2) if consecutive days were missed, those were estimated by simple linear interpolation method using the data of neighboring stations $\left(R^{2}>0.95\right)[20,21]$. Due to urbanization, data from Yaoxian station were used instead of Tongchuan station after 1999; data from Maiji station were used instead of Tianshui station after 2004; data from Fengxiang station were used instead of Baoji station after 2005; data from Jinghe station were used instead of Xian station after 2006. Considering the hydrogeology condition in study area, the distribution of precipitation in rainy season is the driving force for soil erosion and flood for this region, because it is well known that individual rainfall events can contribute approximately $60 \%$ to $90 \%$ of the yearly rainfall total [22]. In general, the flood season refers to June-October, and main flood season refers to July-August [17, 23], in the Loess Plateau. Consequently, this study focused only on precipitation in flood season and main flood season, which are critical agricultural months in the study area.

\section{Methodology}

3.1. Empirical Orthogonal Function. The empirical orthogonal function (EOF) had been used in atmospheric science since the early 1950s and EOF techniques are deeply rooted in statistics, especially in principal component analysis [24, 25]. It provides a compact description of the temporal and spatial variability of a dataset of a single variable in terms of orthogonal components or, also called, statistical "modes." The main features of spatial variability can be outlined using EOF analysis. Essentially, the EOF reduces the data dimensionality, and the smaller set of uncorrelated variables is much easier to understand and further analyze than a larger set of correlated variables. Therefore, the EOF has become a popular tool in meteorology, geology, and geography [26-28]. More details on EOF can be found in Kim et al. [29].

3.2. Ensemble Empirical Mode Decomposition. EEMD, a fundamental part of the Hilbert-Huang transform, is an adaptive method that decomposes a time series into intrinsic mode functions (IMFs) ranging from high- to low-frequency modes, each of which represents a specific frequency range, and a long-term trend [30]. The first IMF has the highest frequency and so on. The sum of these IMFs and the long-term trend reproduces the original time series. The length of the time series determines the number of IMFs. It improves upon the empirical mode decomposition (EMD) method [31, 32], which is an adaptive data analysis method to decompose any 
complicated data series into a finite and often small number of amplitude-frequency modulated oscillatory components. Based on EMD algorithm [31], EEMD method can be briefly described as follows [33]: Step 1: set the ensemble number and the amplitude of the added white noise; Step 2: add a white noise series to the targeted data with the set amplitude; Step 3: decompose the data with added white noise into IMFs; Step 4: repeat Steps 2 and 3 again and again, but with different white noise series each time; then, the final ensemble means of corresponding IMFs of the decompositions are obtained. The basics and effectiveness of this method applied to geophysical data analyses have been documented in many recent works [32-34]. For more details about EMD and EEMD, refer to $\mathrm{Wu}$ and Huang [33]. In this study, the ensemble number is set to 100 and the amplitude of added white noise is set to 0.2 times of standard deviation of that of the data based on suggestion by $\mathrm{Wu}$ and Huang [33].

3.3. Hurst Exponent Analysis. The fractal theory for time series research has been widely applied in climate change, geography, and other fields [35], used to analyze future precipitation trend in this study. The Hurst exponent, estimated by $\mathrm{R} / \mathrm{S}$ analysis, is used as a measure of the long-term memory of the time series. Hurst's index $(H)$ has a strong ability to predict future trends for a time series in relation to past trends, and it has been used to predict hydrological and climatological processes $[8,36]$. $H$ ranges between 0 and 1 , where (1) $H=0.5$ means the various essential elements are completely independent and the change is random; (2) $0.5<H<1$ shows that the time series has a long-term trend which is likely to continue in the future; the closer the $H$ value to 1 , the stronger the continuity; and (3) $0<H<0.5$ also indicates the time series has a long-term trend. However, its future tendency will be the opposite; the closer the $H$ value to 0 , the stronger the reverse tendency.

\section{Results and Discussion}

4.1. Annual Variability of Flood Season Precipitation and Main Flood Season Precipitation. The mean annual precipitation $\left(P_{y}\right)$, precipitation of flood season $\left(P_{f}\right)$, and precipitation of main flood season $\left(P_{\mathrm{mf}}\right)$ were $499.9 \mathrm{~mm}, 383.3 \mathrm{~mm}$, and $211.0 \mathrm{~mm}$ in the research region, respectively (Table 2 ). The $P_{f}$ and $P_{\mathrm{mf}}$ account for $76.67 \%$ and $42.21 \%$ of the annual mean precipitation, respectively. The difference between the maximum and minimum values for each variable was small. The coefficients of variation (CVs) of $P_{y}, P_{f}$, and $P_{\mathrm{mf}}$ were $0.166,0.190$, and 0.254 , respectively, showing that all of their changes are stable. Both the annual average precipitation of flood season and the annual average precipitation of main flood season had no significant trends with a linear increase from 1958 to 2013 (Figure 2). Moreover, there was significant $(P<0.01)$ synchronized variation between the $P_{f}$ and $P_{\mathrm{mf}}$.

4.2. Spatial Patterns of the Precipitation by EOF. The EOFs of the precipitation series in flood season were calculated during 1958-2013. The significance of eigenvectors derived from EOF was tested with North's method [37]. The results showed
TABLE 2: Statistics for annual precipitation $\left(P_{y}\right)$, precipitation of flood season $\left(P_{f}\right)$, and precipitation of main flood season $\left(P_{\mathrm{mf}}\right)$ of the Middle Yellow River from 1958 to 2013.

\begin{tabular}{lccc}
\hline Statistic & $P_{y}(\mathrm{~mm})$ & $P_{f}(\mathrm{~mm})$ & $P_{\mathrm{mf}}(\mathrm{mm})$ \\
\hline Mean & 499.9 & 383.3 & 211.0 \\
Minimum & 335.3 & 231.1 & 103.9 \\
(Year) & $(1997)$ & $(1997)$ & $(1991)$ \\
Maximum & 758.1 & 549.1 & 345.0 \\
(Year) & $(1964)$ & $(1964)$ & $(1958)$ \\
Median & 487.0 & 373.5 & 214.4 \\
Standard deviation & 82.9 & 72.8 & 53.6 \\
Confidence levels (95.0\%) & 22.20 & 19.49 & 14.30 \\
Coefficients of variation & 0.166 & 0.190 & 0.254 \\
\hline
\end{tabular}

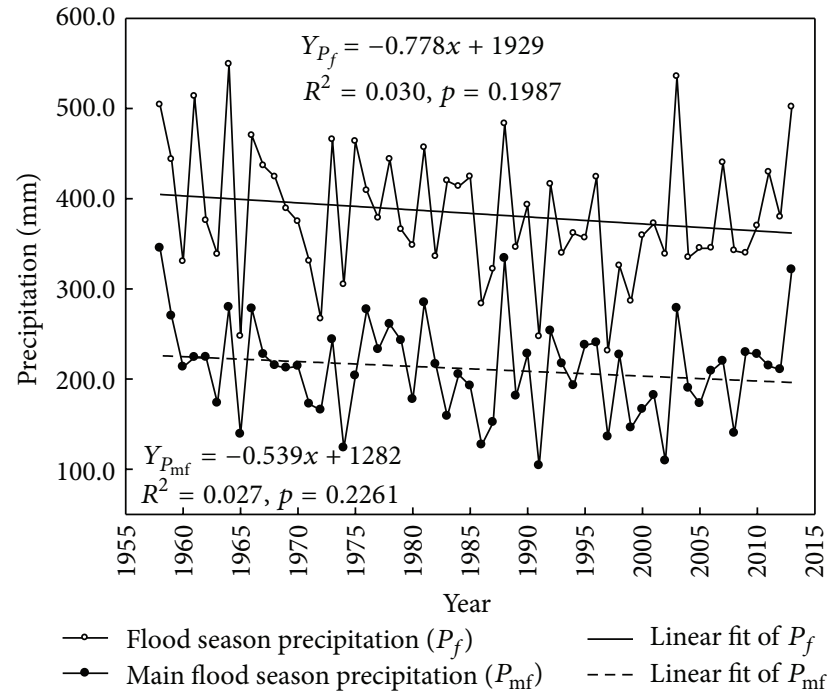

Figure 2: Mean annual flood season and main flood season precipitation in the middle reaches of the Yellow River during 1958-2013.

that the first three eigenvectors were valuable signals both in flood season and main flood season. The first three EOFs during the study period explained approximately $45.2 \%$, $20.8 \%$, and $6.0 \%$ of total variance, respectively. It is generally assumed that those EOFs, whose accumulated variance is more than $70 \%$ of the total variance, have significance in explaining the original data $[28,29]$. In this study, the first three EOFs explained $72 \%$ of the total variance in flood season precipitation. Therefore, the first three EOFs were used in this study to explain the original data. The EOFs of the precipitation series in main flood season were also calculated during the study period. The first three EOFs explained $71.8 \%$ of the total variance in main flood season. Therefore, the first three EOFs of precipitation in flood season were also used in this study to explain the original data.

The first EOF values for $P_{f}$ and $P_{\mathrm{mf}}$ were both positive (Figure 3), which indicated the precipitation was affected by the East Asian monsoon. The second EOFs for both $P_{f}$ and $P_{\mathrm{mf}}$ indicated that precipitation had obvious northsouth differences, and the zero contours for $P_{f}$ and $P_{\mathrm{mf}}$ were 


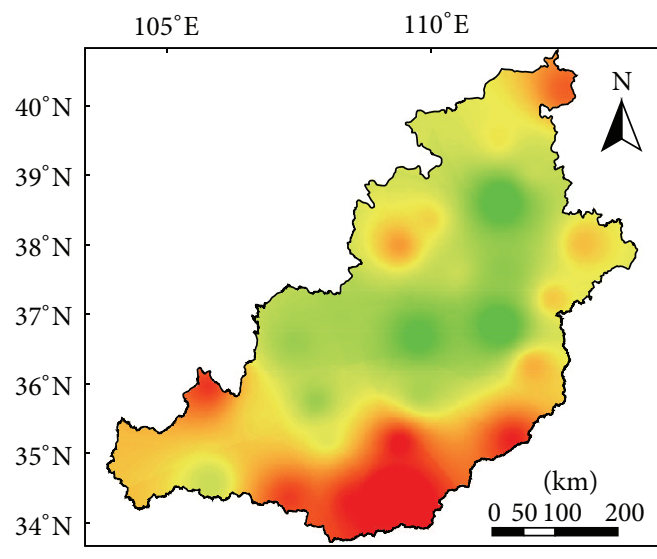

1st EOF of $P_{f}$
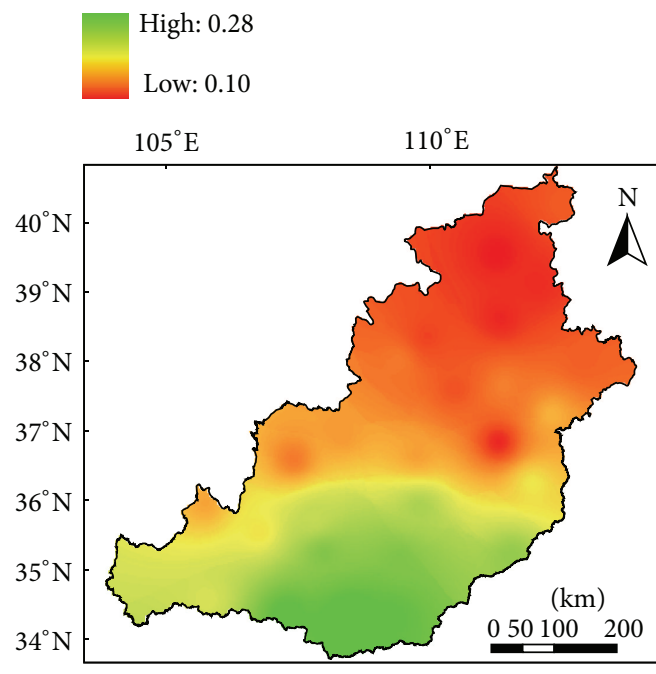

2nd EOF of $P_{f}$

High: 0.44

Low: -0.21

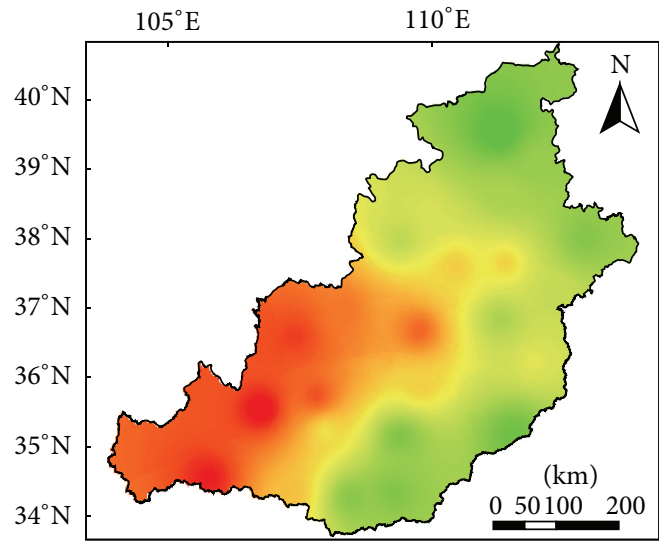

3rd EOF of $P_{f}$

High: 0.37

Low: -0.34

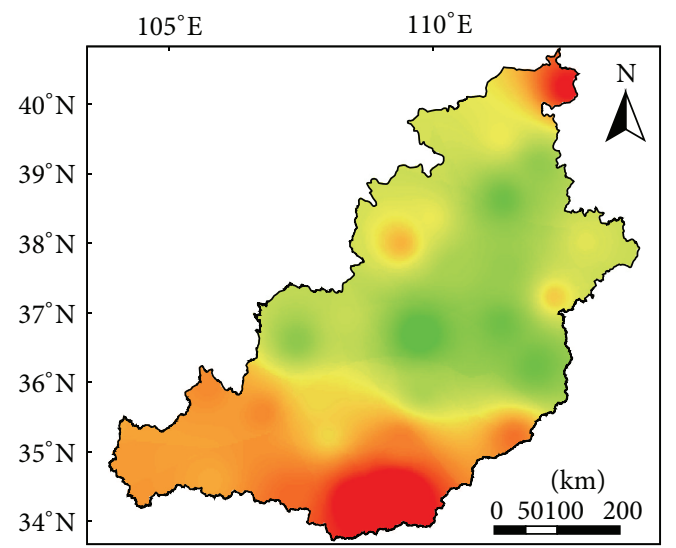

1st EOF of $P_{\mathrm{mf}}$

High: 0.29

Low: 0.06

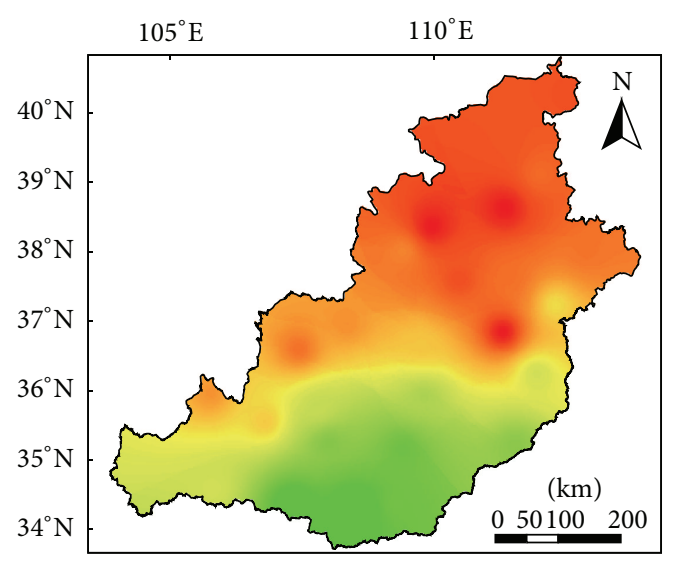

2nd EOF of $P_{\mathrm{mf}}$

High: 0.43

Low: -0.21

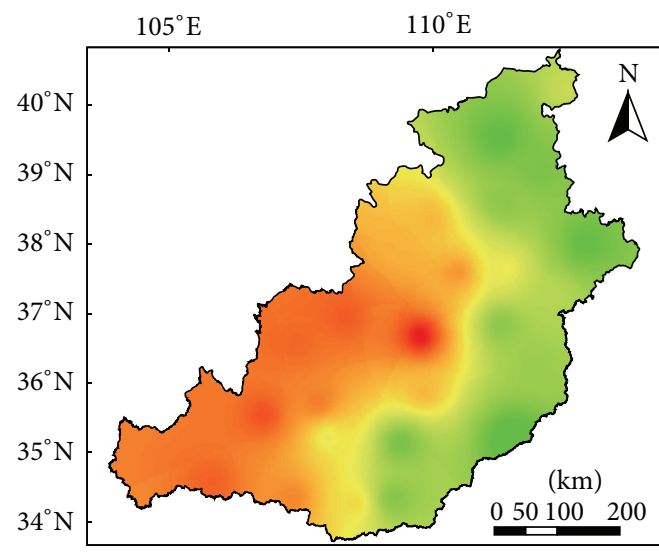

3rd EOF of $P_{\mathrm{mf}}$

High: 0.37

Low: -0.31

FIgURE 3: First three EOFs of the $P_{f}$ and $P_{\mathrm{mf}}$ in MRYR. 

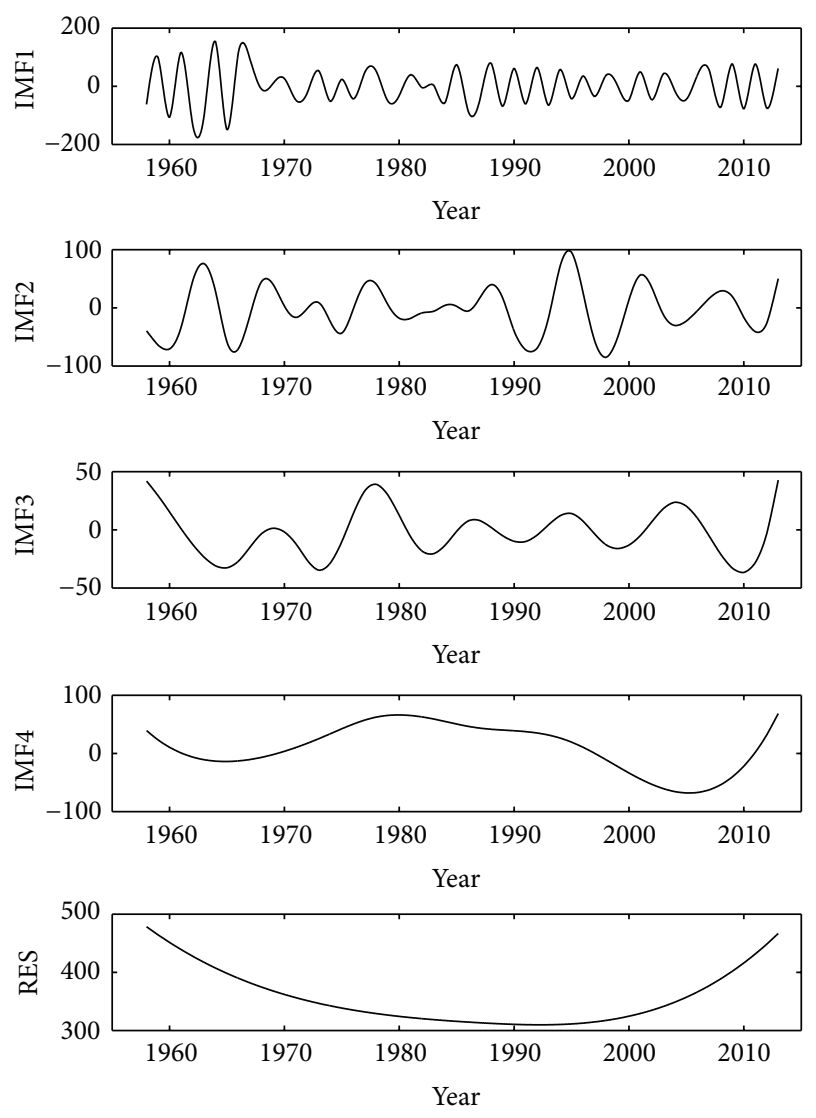

FIgURE 4: EEMD of the $P_{f}$ time series from 1958 to 2013 at the Suide station.

both located in the area around Linfen, Luochuan, Xifeng, and Pingliang. It means that the trend in the precipitation variation is opposite for the northern and the southern areas of the study area, which reveals that precipitation increased in the northern area and decreased in the southern area. In the third EOFs, the zero contours for $P_{f}$ and $P_{\mathrm{mf}}$ were both located in the area around Yulin, Suide, Luochuan, and Wugong, which indicated an approximately east-west direction.

4.3. Decomposing Annual Flood Season and Main Flood Season Rainfall Time Series Using EEMD. By employing the EEMD technique, the original annual $P_{f}$ and $P_{\mathrm{mf}}$ time series from 26 stations are decomposed into four independent IMFs and one residue, respectively. For example, the results for the Suide station are illustrated in Figures 4 and 5. It can be observed that precipitation data are decomposed into IMFs, and we can also see that the IMFs present changing frequencies, amplitudes, and wavelengths. For all IMFs, IMF1 has the maximum amplitude, highest frequency, and shortest wavelength. The following IMF components decrease in the amplitude and frequency and increase in the wavelength. The last residue (RES) is a mode slowly varying around the longterm average.

There are few periodic variabilities of $P_{f}$ in the MRYR. Both the periodicity properties of regional precipitation
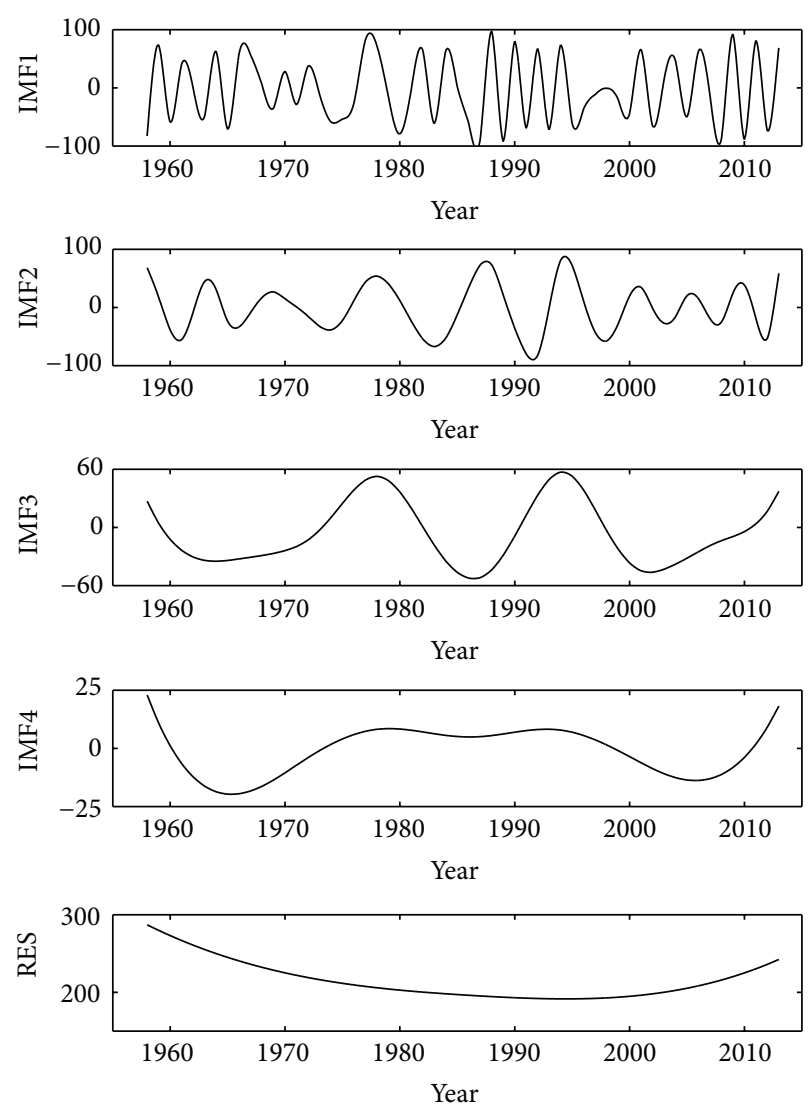

FIgURE 5: EEMD of the $P_{\mathrm{mf}}$ time series from 1958 to 2013 at the Suide station.

series and the periodicity properties of $P_{f}$ at each station show few periodic variabilities (Table 3 ). The periodicity of IMF1 at each station ranges from a minimum of 2.3 to a maximum of 3.1, the periodicity of IMF2 at each station ranges from a minimum of 4.3 to a maximum of 6.2 , the periodicity of IMF3 at each station ranges from a minimum of 8 to a maximum of 14, and the periodicity of IMF4 at each station ranges from a minimum of 18.6 to a maximum of 48.1 . However, only the periodicity of IMF2 at Linfen station and the periodicity of IMF4 at Suide, Lishi, and Yan'an station pass the statistical significance.

The periodic variability of $P_{\mathrm{mf}}$ at each mode (Table 4) is similar to that in $P_{f}$. Only the periodicity of IMF1 at Hengshan station, the periodicity of IMF2 at Xifeng station, the periodicity of IMF3 at Suide and Xixian station, and the periodicity of IMF4 at Lishi, Yan'an, Yuncheng, and Baoji station pass the statistical significance. It also means that there is less periodic variability of $P_{\mathrm{mf}}$ in the MRYR.

Though there were few stations passing the significant test for precipitation period, the IMF2 component of Linfen station for $P_{f}$, the IMF1 component of Hengshan station, and the IMF2 component of Xifeng station for $P_{\mathrm{mf}}$ in Tables 3 and 4 showed that there were obvious periodic variability within 3-4 years and 6-8 years, respectively. According to multiple timescale analysis of sea surface temperature (SST) data in Niño-3 region $\left(5^{\circ} \mathrm{N}-5^{\circ} \mathrm{S}, 150^{\circ}-90^{\circ} \mathrm{W}\right)$ during $1881-2002$ [38], 
TABLE 3: The mean periods of various time-scale components for $P_{f}$ during 1958-2013 in the MRYR obtained by the EEMD.

\begin{tabular}{|c|c|c|c|c|}
\hline Station (abbreviation) & IMF1 & IMF2 & IMF3 & IMF4 \\
\hline Regional precipitation (MRYR) & 2.5 & 4.3 & 9.3 & 27.9 \\
\hline Youyu (YY) & 2.3 & 5.6 & 11.2 & 21.2 \\
\hline Hequ (HQ) & 2.7 & 5.6 & 11.2 & 27.9 \\
\hline Wuzhai (WZ) & 2.8 & 5.6 & 11.2 & 19.2 \\
\hline Xingxian (XX) & 2.5 & 5.6 & 11.2 & 24.2 \\
\hline Yulin (YL) & 2.9 & 5.6 & 11.2 & 29.0 \\
\hline Taiyuan (TY) & 2.7 & 5.1 & 9.3 & 21.4 \\
\hline Hengshan (HS) & 2.8 & 4.7 & 8.0 & 27.3 \\
\hline Suide (SD) & 2.5 & 5.6 & 9.3 & $28.1^{* *}$ \\
\hline Lishi (LS) & 2.5 & 5.6 & 11.2 & $46.1^{*}$ \\
\hline Jiexiu (JX) & 2.5 & 4.3 & 9.3 & 27.8 \\
\hline Wuqi (WQ) & 2.5 & 5.6 & 9.3 & 18.6 \\
\hline Yan’an (YA) & 2.4 & 5.6 & 9.3 & $27.7^{*}$ \\
\hline Xixian (XX) & 2.3 & 4.7 & 9.3 & 29.0 \\
\hline Linfen (LF) & 2.7 & $5.6^{*}$ & 9.3 & 22.7 \\
\hline Huanxian (HX) & 2.4 & 5.6 & 11.2 & 28.3 \\
\hline Luochuan (LC) & 2.7 & 4.7 & 9.3 & 26.5 \\
\hline Yuncheng (YC) & 2.8 & 5.1 & 11.2 & 30.3 \\
\hline Xiji (XJ) & 2.9 & 6.2 & 14.0 & 27.9 \\
\hline Pingliang (PL) & 2.3 & 4.7 & 9.3 & 18.7 \\
\hline Xifeng (XF) & 2.8 & 6.2 & 11.2 & 48.1 \\
\hline Changwu (CW) & 2.8 & 5.1 & 9.3 & 23.4 \\
\hline Tongchuan (TC) & 3.1 & 5.6 & 11.2 & 27.0 \\
\hline Tianshui (TS) & 2.7 & 4.7 & 11.2 & 28.3 \\
\hline Baoji (BJ) & 2.7 & 5.1 & 9.3 & 29.5 \\
\hline Wugong (WG) & 2.8 & 4.7 & 8.0 & 23.5 \\
\hline Xi'an (XA) & 2.9 & 5.6 & 9.3 & 26.9 \\
\hline
\end{tabular}

Note: $*$ and $* *$ represent significant trend tested at 0.1 and 0.05 significant levels, respectively.

there was also obvious periodic variability within 3-4 years and 6-8 years. Hence, the high-frequency components of annual flood season and main flood season precipitation series were consistent with SST which demonstrated that the short-term variation of annual flood season and main flood season precipitation in some area of the study area may be affected by SST. Further study will be required to explain the observed precipitation periodicities associating with the influencing climatic factors.

4.4. Future Trend of Flood Season and Main Flood Season Precipitation. The Hurst index provides statistical predictions concerning future trend. The Hurst index based on the $P_{f}$ and $P_{\mathrm{mf}}$ time series at 26 stations from 1958 to 2013 is shown in Table 5. The $H$ value of $P_{f}$ ranges from a minimum of 0.49 to a maximum of 0.73 . An $H$ value which is greater than 0.5 refers to the persistence of the series, which indicates the same trend in the time series in the future, with a greater value for more persistence. This means that there is a long-term persistence
TABLE 4: The mean periods of various time-scale components for $P_{\mathrm{mf}}$ during 1958-2013 in the MRYR obtained by the EEMD.

\begin{tabular}{|c|c|c|c|c|}
\hline Station (abbreviation) & IMF1 & IMF2 & IMF3 & IMF4 \\
\hline Regional precipitation (MRYR) & 2.8 & 5.6 & 9.3 & 18.8 \\
\hline Youyu (YY) & 2.4 & 4.3 & 9.3 & 35.1 \\
\hline Hequ (HQ) & 2.8 & 6.2 & 14.0 & 29.4 \\
\hline Wuzhai (WZ) & 2.8 & 5.6 & 11.2 & 27.6 \\
\hline Xingxian (XX) & 2.5 & 5.1 & 11.2 & 18.5 \\
\hline Yulin (YL) & 2.8 & 5.6 & 11.2 & 32.9 \\
\hline Taiyuan (TY) & 2.8 & 5.1 & 9.3 & 18.6 \\
\hline Hengshan (HS) & $3.3^{*}$ & 6.2 & 14.0 & 42.5 \\
\hline Suide (SD) & 2.8 & 6.2 & $18.7^{*}$ & 24.9 \\
\hline Lishi (LS) & 2.8 & 5.1 & 11.2 & $39.6^{* *}$ \\
\hline Jiexiu (JX) & 2.7 & 5.6 & 9.3 & 27.8 \\
\hline Wuqi (WQ) & 2.5 & 4.7 & 9.3 & 19.2 \\
\hline Yan’an (YA) & 2.8 & 5.1 & 14.0 & $27.9^{*}$ \\
\hline Xixian (XX) & 2.7 & 5.1 & $14.0^{* *}$ & 47.6 \\
\hline Linfen (LF) & 2.7 & 5.6 & 9.3 & 18.6 \\
\hline Huanxian (HX) & 2.5 & 7.0 & 14.0 & 29.9 \\
\hline Luochuan (LC) & 2.7 & 5.6 & 11.2 & 27.1 \\
\hline Yuncheng (YC) & 3.1 & 6.2 & 11.2 & $50.1^{*}$ \\
\hline Xiji (XJ) & 2.8 & 6.2 & 11.2 & 19.7 \\
\hline Pingliang (PL) & 2.8 & 5.6 & 14.0 & 30.5 \\
\hline Xifeng (XF) & 2.8 & $6.2^{*}$ & 9.3 & 47.8 \\
\hline Changwu (CW) & 2.5 & 5.1 & 8.0 & 24.2 \\
\hline Tongchuan (TC) & 3.1 & 6.2 & 11.2 & 28.6 \\
\hline Tianshui (TS) & 2.3 & 4.3 & 9.3 & 25.8 \\
\hline Baoji (BJ) & 2.7 & 5.1 & 11.2 & $26.3^{*}$ \\
\hline Wugong (WG) & 2.5 & 5.1 & 9.3 & 26.3 \\
\hline Xi'an (XA) & 2.7 & 5.6 & 9.3 & 25.3 \\
\hline
\end{tabular}

Note: $*$ and $* *$ represent significant trend tested at 0.1 and 0.05 significant levels, respectively.

in the variability of precipitation. Most of the stations in the study area have long-term persistence. The stations where there is no long-term persistence in the variability $(H<0.5)$ are Wuzhai and Pingliang station. The main flood season precipitation in the region shows the $H$ value range from a minimum of 0.51 to a maximum of 0.72 , indicating the trend will be maintained in the future. The $H$ value of 0.44 for Pingliang station indicates an opposite precipitation trend in the future. The present trends of $P_{f}$ and $P_{\mathrm{mf}}$ for most of the stations are decreasing (see Supplementary Material available online at http://dx.doi.org/10.1155/2016/9451614). According to above results of Hurst index, the trends of future precipitation in these stations will be persistent.

\section{Conclusions}

In this paper, analysis of the trends, periodic variability, and temporal-spatial patterns of the flood season precipitation and main flood season precipitation in the middle reaches of the Yellow River support the following conclusions. 
TABle 5: Hurst exponent analysis for $P_{f}$ and $P_{\mathrm{mf}}$ during 1958-2013 in the MRYR.

\begin{tabular}{lcc}
\hline Station (abbreviation) & $H_{1}$ & $H_{2}$ \\
\hline Youyu (YY) & 0.58 & 0.64 \\
Hequ (HQ) & 0.59 & 0.59 \\
Wuzhai (WZ) & 0.49 & 0.58 \\
Xingxian (XX) & 0.58 & 0.58 \\
Yulin (YL) & 0.65 & 0.61 \\
Taiyuan (TY) & 0.60 & 0.56 \\
Hengshan (HS) & 0.62 & 0.72 \\
Suide (SD) & 0.70 & 0.61 \\
Lishi (LS) & 0.60 & 0.58 \\
Jiexiu (JX) & 0.72 & 0.61 \\
Wuqi (WQ) & 0.52 & 0.63 \\
Yanan (YA) & 0.64 & 0.56 \\
Xixian (XX) & 0.65 & 0.56 \\
Linfen (LF) & 0.67 & 0.61 \\
Huanxian (HX) & 0.58 & 0.53 \\
Luochuan (LC) & 0.68 & 0.67 \\
Yuncheng (YC) & 0.62 & 0.61 \\
Xiji (XJ) & 0.68 & 0.56 \\
Pingliang (PL) & 0.49 & 0.44 \\
Xifeng (XF) & 0.58 & 0.60 \\
Changwu (CW) & 0.53 & 0.51 \\
Tongchuan (TC) & 0.59 & 0.53 \\
Tianshui (TS) & 0.63 & 0.64 \\
Baoji (BJ) & 0.60 & 0.66 \\
Wugong (WG) & 0.73 & 0.70 \\
Xian (XA) & 0.51 & 0.56 \\
\hline Note $H_{1}$ &
\end{tabular}

Note: $H_{1}$ represented $H$ index of $P_{f} ; H_{2}$ represented $H$ index of $P_{\mathrm{mf}}$.

The first three EOFs for $P_{f}$ and $P_{\mathrm{mf}}$ were selected in this study to identify the spatial-temporal variations of the predominant components. The results indicate that the first EOFs values are all positive, which indicate that the precipitation is affected by similar large-scale circulation patterns. The second EOFs indicate north-south patterns located in the area around Linfen, Luochuan, Xifeng, and Pingliang. Moreover, the third EOFs display east-west patterns located in the area around Yulin, Suide, Luochuan, and Wugong for the study area.

The $P_{f}$ and $P_{\mathrm{mf}}$ in the middle reaches of the Yellow River are subject to a quasi-3-year, quasi-6-year interannual periodical feature based on the EEMD analysis, whereas interdecadal scale periods are dominated by quasi-11-year and quasi-28-year. However, periodicity in most study areas is not significant.

Hurst exponent $(H)$ analysis indicates that the $H$ value is greater than $0.5 \mathrm{in} \mathrm{most} \mathrm{stations} \mathrm{both} \mathrm{for} P_{f}$ and $P_{\mathrm{mf}}$. Thus, the precipitation in $P_{f}$ and $P_{\mathrm{mf}}$ will continue the current trends in the future.

\section{Conflict of Interests}

The authors declare that there is no conflict of interests regarding the publication of this paper.

\section{Acknowledgments}

This research was supported by the National Natural Science Foundation of China [41371277 and 41271295], the Key Research Program of the Chinese Academy of Sciences [KZZD-EW-04], and Special Fund for Water Conservancy Scientific Research in the Public Welfare [201501049]. The authors were grateful to the anonymous reviewers and the editors who helped improved the quality of this paper.

\section{References}

[1] C. Rodriguez-Puebla, A. H. Encinas, S. Nieto, and J. Garmendia, "Spatial and temporal patterns of annual precipitation variability over the Iberian Peninsula," International Journal of Climatology, vol. 18, no. 3, pp. 299-316, 1998.

[2] I. A. Tošić, "Spatial and temporal variability of winter and summer precipitation over Serbia and Montenegro," Theoretical and Applied Climatology, vol. 77, no. 1-2, pp. 47-56, 2004.

[3] V. Barros, E. Castañeda, and M. Doyle, "Recent precipitation trends in Southern South America to the east of the Andes: an indication of a mode of climatic variability," in Southern Hemisphere Paleo and Neoclimates, p. 381, Springer, Berlin, Germany, 2000.

[4] P. Coulibaly, "Spatial and temporal variability of Canadian seasonal precipitation (1900-2000)," Advances in Water Resources, vol. 29, no. 12, pp. 1846-1865, 2006.

[5] H. Feidas, C. Noulopoulou, T. Makrogiannis, and E. Bora-Senta, "Trend analysis of precipitation time series in Greece and their relationship with circulation using surface and satellite data: 1955-2001," Theoretical and Applied Climatology, vol. 87, no. 1-4, pp. 155-177, 2007.

[6] R. Modarres and V. de P. R. da Silva, "Rainfall trends in arid and semi-arid regions of Iran," Journal of Arid Environments, vol. 70, no. 2, pp. 344-355, 2007.

[7] Q. Liu, Z. Yang, and B. Cui, "Spatial and temporal variability of annual precipitation during 1961-2006 in Yellow River Basin, China," Journal of Hydrology, vol. 361, no. 3-4, pp. 330-338, 2008.

[8] Q. H. Li, Y. N. Chen, Y. J. Shen, X. G. Li, and J. H. Xu, "Spatial and temporal trends of climate change in Xinjiang, China," Journal of Geographical Sciences, vol. 21, no. 6, pp. 1007-1018, 2011.

[9] C.-F. Xue, W. Hou, J.-H. Zhao, and S.-G. Wang, “The application of ensemble empirical mode decomposition method in multiscale analysis of region precipitation and its response to the climate change," Acta Physica Sinica, vol. 62, no. 10, Article ID 109203, 2013.

[10] S. Yu, J. Yang, G. Liu, R. Yao, and X. Wang, "Improvement for the multi-scale periodic characteristics revealing of precipitation signals and its impact assessment on soil hydrological process by combining HHT and CWT approaches," Natural Hazards and Earth System Science, vol. 15, no. 3, pp. 393-407, 2015.

[11] P. Gao, X.-M. Mu, F. Wang, and R. Li, "Changes in streamflow and sediment discharge and the response to human activities in the middle reaches of the Yellow River," Hydrology and Earth System Sciences, vol. 15, no. 1, pp. 1-10, 2011.

[12] D. C. Ran, "Summary on runoff and sedimentation variation research from Hekouzhen to Longmen in the Middle Reaches of the Yellow River," Journal of Sediment Research, no. 3, pp. 7281, 2000 (Chinese). 
[13] J. X. Xu, "Recent tendency of sediment reduction in the middle Yellow River and some countermeasures," Journal of Sediment Research, no. 2, pp. 5-10, 2004 (Chinese).

[14] J. X. Xu, "Trend of sediment yield in the coarser sediment producing area in the middle Yellow River Basin in the Period 1997-2007 and the formative cause," Journal of Soil and Water Conservation, vol. 24, no. 1, pp. 1-7, 2010 (Chinese).

[15] X. Mu, X. Zhang, H. Shao et al., "Dynamic changes of sediment discharge and the influencing factors in the yellow river, China, for the recent 90 years," Clean-Soil, Air, Water, vol. 40, no. 3, pp. 303-309, 2012.

[16] K. Liang, C. Liu, X. Liu, and X. Song, "Impacts of climate variability and human activity on streamflow decrease in a sediment concentrated region in the Middle Yellow River," Stochastic Environmental Research and Risk Assessment, vol. 27, no. 7, pp. 1741-1749, 2013.

[17] Y. He, X. M. Mu, G. J. Zhao, and P. Gao, "Variation of erosive rainfall and extreme rainfall based on processes of sediment discharge in the reach of Hekou-Tongguan, Yellow River," Journal of Sediment Research, no. 2, pp. 53-59, 2015 (Chinese).

[18] B. J. Fu and H. Gulinck, "Land evaluation in an area of severe erosion: the Loess Plateau of China," Land Degradation and Development, vol. 5, no. 1, pp. 33-40, 1994.

[19] T. C. Peterson, D. R. Easterling, T. R. Karl et al., "Homogeneity adjustments of in situ atmospheric climate data: a review," International Journal of Climatology, vol. 18, no. 13, pp. 1493$1517,1998$.

[20] F. Q. Jiang, X. M. Li, B. G. Wei, R. J. Hu, and Z. Li, “Observed trends of heating and cooling degree-days in Xinjiang Province, China," Theoretical and Applied Climatology, vol. 97, no. 3-4, pp. 349-360, 2009.

[21] X. Li, F. Jiang, L. Li, and G. Wang, "Spatial and temporal variability of precipitation concentration index, concentration degree and concentration period Xinjiang, China," International Journal of Climatology, vol. 31, no. 11, pp. 1679-1693, 2011.

[22] Z. Li, F.-L. Zheng, W.-Z. Liu, and D. C. Flanagan, "Spatial distribution and temporal trends of extreme temperature and precipitation events on the Loess Plateau of China during 19612007," Quaternary International, vol. 226, no. 1-2, pp. 92-100, 2010.

[23] Z. Li, "Analysis on characteristics and reasons of sediment discharge in the Hekou-Longmen Region of the Yellow River," Yellow River, vol. 30, no. 8, pp. 41-42, 2008.

[24] J. E. Kutzbach, "Empirical eigenvectors of sea-level pressure, surface temperature and precipitation complexes over North America," Journal of Applied Meteorology, vol. 6, no. 5, pp. 791$802,1967$.

[25] G. R. North, T. L. Bell, R. F. Cahalan, and F. J. Moeng, "Sampling errors in the estimation of empirical orthogonal functions," Monthly Weather Review, vol. 110, no. 7, pp. 699-706, 1982.

[26] K. Y. Kim and G. R. North, "EOF analysis of surface temperature field in a stochastic climate model," Journal of Climate, vol. 6, no. 9, pp. 1681-1690, 1993.

[27] R. Tomozeiu, M. Lazzeri, and C. Cacciamani, "Precipitation fluctuations during the winter season from 1960 to 1995 over Emilia-Romagna, Italy," Theoretical and Applied Climatology, vol. 72, no. 3-4, pp. 221-229, 2002.

[28] X. Y. Song, L. J. Li, G. B. Fu et al., "Spatial-temporal variations of spring drought based on spring-composite index values for the Songnen Plain, Northeast China," Theoretical and Applied Climatology, vol. 116, no. 3-4, pp. 371-384, 2014.
[29] D. H. Kim, C. Yoo, and T.-W. Kim, "Application of spatial EOF and multivariate time series model for evaluating agricultural drought vulnerability in Korea," Advances in Water Resources, vol. 34, no. 3, pp. 340-350, 2011.

[30] Z. H. Wu, N. E. Huang, and X. Y. Chen, "The multi-dimensional ensemble empirical mode decomposition method," Advances in Adaptive Data Analysis. Theory and Applications, vol. 1, no. 3, pp. 339-372, 2009.

[31] N. E. Huang, Z. Shen, S. R. Long et al., "The empirical mode decomposition and the Hilbert spectrum for nonlinear and non-stationary time series analysis," Proceedings of the Royal Society of London A: Mathematical, Physical and Engineering Sciences, vol. 454, no. 1971, pp. 903-995, 1998.

[32] N. E. Huang and Z. Wu, "A review on Hilbert-Huang transform: method and its applications to geophysical studies," Reviews of Geophysics, vol. 46, no. 2, Article ID RG2006, 2008.

[33] Z. Wu and N. E. Huang, "Ensemble empirical mode decomposition: a noise-assisted data analysis method," Advances in Adaptive Data Analysis, vol. 1, no. 1, pp. 1-41, 2009.

[34] C. Qian, Z. W. Yan, and C. B. Fu, "Climatic changes in the Twenty-four Solar Terms during 1960-2008," Chinese Science Bulletin, vol. 57, no. 2-3, pp. 276-286, 2012.

[35] S. Rehman, "Study of Saudi Arabian climatic conditions using Hurst exponent and climatic predictability index," Chaos, Solitons \& Fractals, vol. 39, no. 2, pp. 499-509, 2009.

[36] G. Sakalauskiene, "The Hurst phenomenon in hydrology," Environmental Research, Engineering and Management, vol. 3, no. 25, pp. 16-20, 2003.

[37] G. R. North, T. L. Bell, R. F. Cahalan, and F. J. Moeng, "Sampling errors in the estimation of empirical orthogonal functions," Monthly Weather Review, vol. 110, no. 7, pp. 699-706, 1982.

[38] X. Sun and Z. S. Lin, "A new technology HHT and its diagnosis for ENSO," Meteorological Monthly, vol. 32, no. 9, pp. 17-22, 2006 (Chinese). 

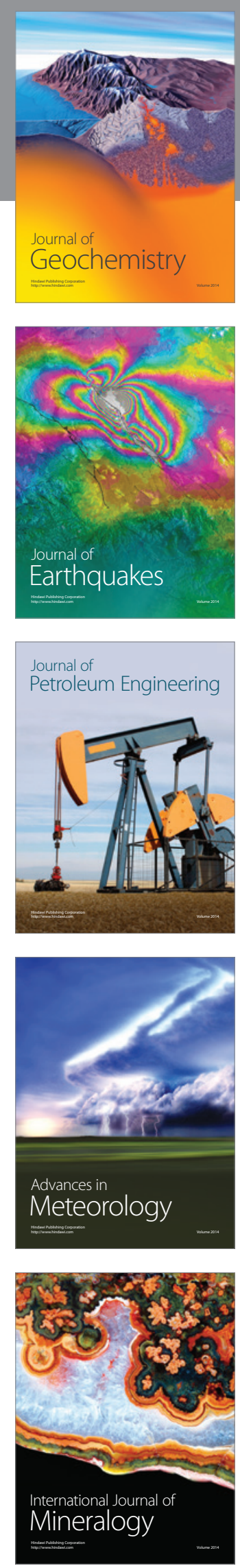
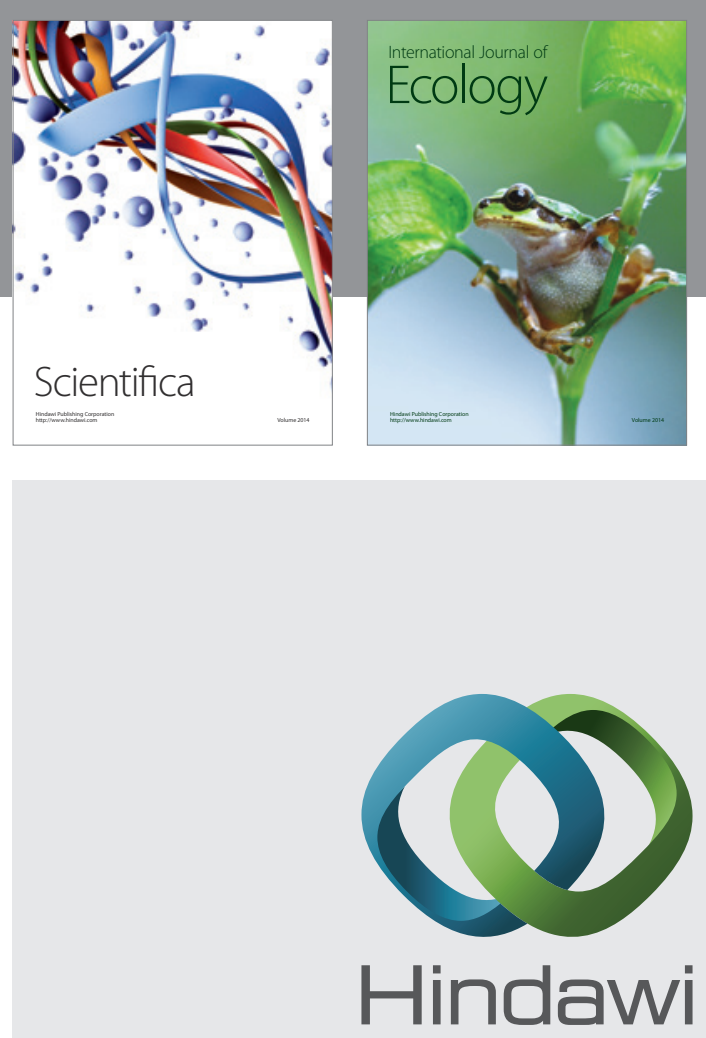

Submit your manuscripts at

http://www.hindawi.com
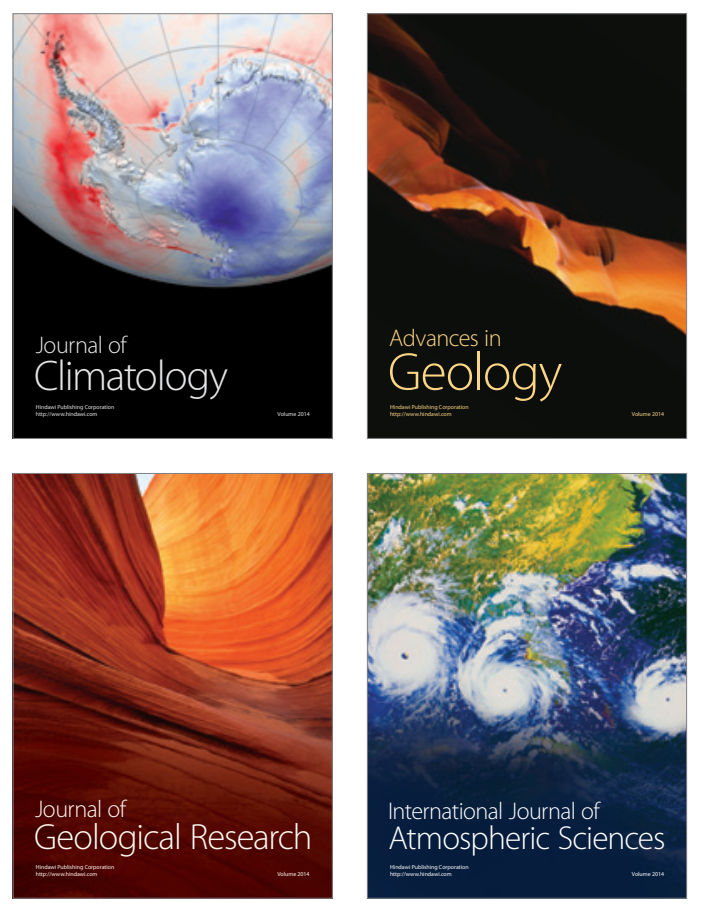

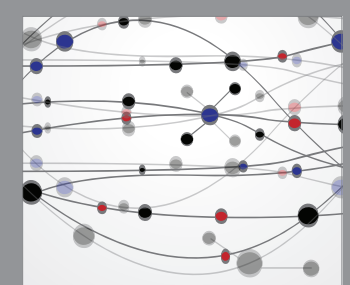

The Scientific

\section{World Journal}
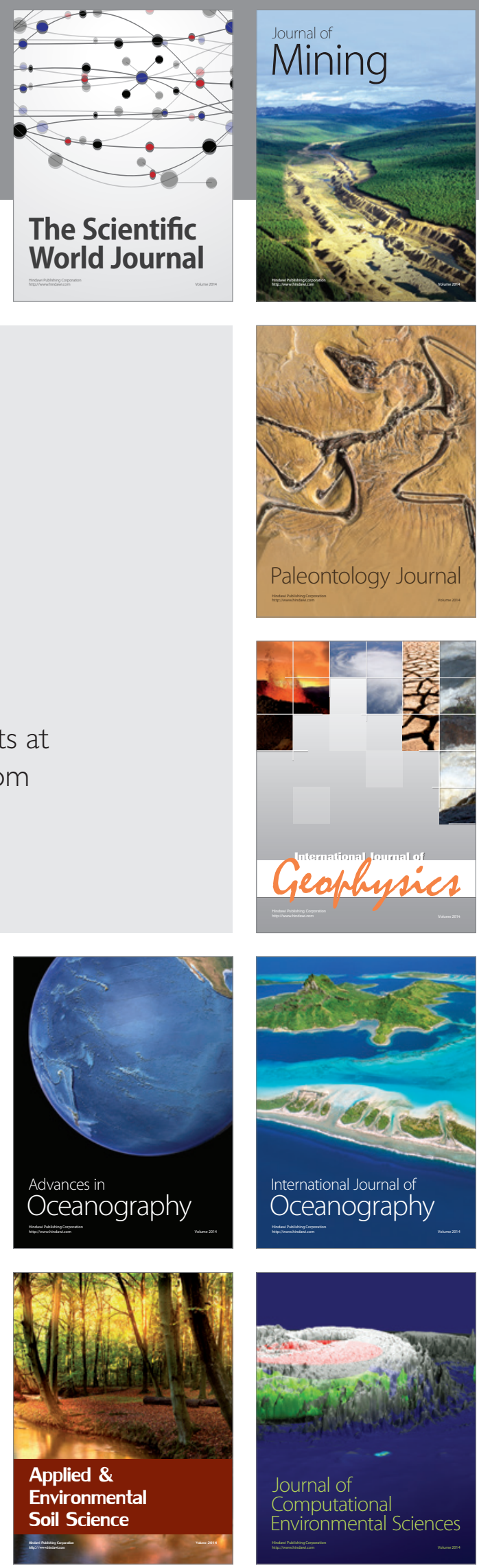